\title{
Phenotypes and genotypes of insulin-like growth factor 1, IGF-binding protein-3 and cancer risk: evidence from 96 studies
}

\author{
Wensen Chen ${ }^{1,2,4}$, Sumin Wang ${ }^{3,4}$, Tian $\operatorname{Tian}^{1}$, Jianling Bai ${ }^{1}$, Zhibin $\mathrm{Hu}^{1}$, Yan $\mathrm{Xu}^{1}$,
} Jing Dong ${ }^{1}$, Feng $\mathrm{Chen}^{1}$, Xinru Wang ${ }^{1}$ and Hongbing Shen*,1

\author{
${ }^{1}$ Laboratory of Reproductive Medicine, Cancer Center, Nanjing Medical University, Nanjing, China; ${ }^{2}$ Section of \\ Disinfection and Vector Control, Jiangsu Province Centre for Disease Prevention and Control, Nanjing, China; ${ }^{3}$ Nanjing \\ Maternity and Child Health Hospital of Nanjing Medical University, Nanjing, China
}

Insulin-like growth factor 1 (IGF1) and its main binding protein, IGF-binding protein 3 (IGFBP3), play an important role in cancer development. Circulating levels and functional polymorphisms of IGF1 and IGFBP3 may be biomarkers of cancer development. However, the results of published studies remain conflicting rather than conclusive. We searched MEDLINE and EMBASE databases for all published studies related to circulating levels and polymorphisms of IGF1 and IGFBP3 and cancer risk. In all, 96 studies and over 110000 subjects were available for this meta-analysis. Higher IGF1 circulating levels significantly increased $15 \%$ of cancer risk (odds ratio (OR), 1.15, 95\% confidence interval (CI), 1.03-1.29), especially among prostate, pre-menopausal breast and colorectal cancer patients, whereas higher concentrations of IGFBP3 significantly decreased the risk of advanced prostate cancer by $56 \%(\mathrm{OR}, 0.44,95 \% \mathrm{CI}, 0.25-0.77)$. Meanwhile, IGFBP3 -202CC genotype was associated with an increased risk of prostate cancer with borderline significance (OR, 1.18, 95\% Cl, 0.99-1.41). Genotype-phenotype correlation analyses showed that circulating levels of IGFBP3 could be modified by its promoter polymorphism $A-202 C(P<0.001)$. In conclusion, circulating levels of IGF1, IGFBP3 and IGFBP3 A-202C play a crucial role in carcinogenesis and could serve as susceptibility biomarkers for cancer development.

European Journal of Human Genetics (2009) 17, 1668-1675; doi:10.1038/ejhg.2009.86; published online 3 June 2009

Keywords: IGF1; IGFBP3; polymorphism; cancer risk; meta-analysis

Introduction

Insulin-like growth factor-1 (IGF1) is an important regulator of cellular proliferation, differentiation and apoptosis. ${ }^{1}$ More than $90 \%$ of the circulating IGF1 is bound to insulin-like growth factor-binding protein-3 (IGFBP3), which regulates the biological activity of IGF1. It was

*Correspondence: Professor H Shen, Laboratory of Reproductive Medicine, Cancer Center, Nanjing Medical University, Nanjing 210029, China.

Tel: + 86258686 2756; Fax: +86 258686 2756;

E-mail: hbshen@njmu.edu.cn

${ }^{4}$ These authors contributed equally to this work

Received 15 September 2008; revised 3 February 2009; accepted 26 February 2009; published online 3 June 2009 reported that there was a great interindividual variation in serum levels of IGF1 and IGFBP3 ${ }^{2}$ and several epidemiological observations showed that circulating levels of IGF1, IGFBP3 and their molar ratio were associated with risk of common cancers. ${ }^{3-5}$ Twin studies suggested a genetic basis accounting for nearly $60 \%$ of the interindividual variability of circulating levels of IGF1 and IGFBP3. ${ }^{6}$ Several genetic polymorphisms were identified to influence the circulating levels of IGF1 and IGFBP3. For example, the number of (CA)n dinucleotide repeat at $1 \mathrm{~kb}$ upstream from the transcription start site of IGF1 was found to be inversely correlated with the transcription activity of IGF1.7,8 Meanwhile, two genetic variants were reported to link to IGFBP3 levels..$^{9-11}$ One is a promoter single nucleotide 
polymorphism (SNP) located at position -202 (rs2854744, $\mathrm{A}>\mathrm{C}$ ) from the transcription start site of IGFBP $3,{ }^{9}$ resulting in a reduced promoter activity and decreased IGFBP3 levels. ${ }^{9,10}$ The other one is a non-synonymous substitution, Gly32Ala (rs2854746, G>C), and the presence of the variant 32Ala allele was inversely associated with IGFBP3 levels. ${ }^{11}$

Recently, molecular epidemiological studies showed that these SNPs, such as IGF1 (CA)n, IGFBP3 A-202C and Gly32Ala, were associated with susceptibility of diverse cancers, including breast ${ }^{12-14}$ prostate, $^{15}$ colorectal $^{16}$ and gastric cancers. ${ }^{17}$ However, the results were controversial rather than conclusive. ${ }^{18,19}$ To estimate the effect of phenotypes (circulating levels) and genotypes (functional SNPs) of IGF1 and IGFBP3 associated with the risk of multiple cancer sites as well as individual cancers, we conducted a systematic meta-analysis with 96 published studies.

\section{Subjects and methods}

\section{Identification and eligibility of studies}

We included all the studies with epidemiological study designs of case-control, cohort, or cross-sectional studies, published to date on the associations of phenotypes (circulating concentrations) and genotypes (SNPs) of IGF1 and IGFBP3 with cancer risk. Eligible studies were identified by searching the electronic literatures (MEDLINE and EMBASE) for relevant reports (last search date on April 30, 2008, using the search terms 'IGF* and cancer' and 'IGF* polymorphisms and cancer') by two independent investigators (W Chen and S Wang). Additional studies were identified by a hand search of references of original studies or review articles on this topic. ${ }^{3,4,18-22}$ All the available studies should describe their data with ORs and 95\% CIs, and have at least three categories (for example, tertiles to quintiles) of IGF1 and IGFBP3 levels. If studies had partly overlapped subjects, only the one with a larger sample size was selected. The two investigators (W Chen and S Wang) reached coherence on all the selected studies included in the final analyses.

As a result, 96 published studies were eligible for further analyses. Sixty-five studies were available for phenotype analysis (63 for IGF1, 60 for IGFBP3 and 21 for IGF1/ IGFBP3 molar ratio), including 15212 cases and 27913 controls. Pre- and post-menopausal breast cancers were evaluated separately. For IGF1, two studies had only stratified information by age or sex, so we divided them into two substudies. ${ }^{23,24}$ Twenty-seven studies investigated the potential functional polymorphisms (19 for IGF1 $(\mathrm{CA})_{\mathrm{n}}, 16$ for IGFBP3 A-202C and 6 for IGFBP3 Gly32Ala), including 27852 cases and 40354 controls. One multicenter study ${ }^{14}$ was included and two duplicated articles were excluded for the association between genotypes and cancer risk. $^{25,26}$ Nine studies were available for genotypephenotype correlation analysis.

\section{Data extraction}

All the selected studies presented their main findings with ORs and 95\% CIs in terms of phenotypes (levels of IGF1, IGFBP3 or IGF1/IGFBP3 molar ratio) and cancer risk. Genotype frequencies were collected to pool the polymorphism data. In the genotype-phenotype correlation analysis, to avoid the influence of IGF1 or IGFBP3 levels from therapeutic effects, we only analyzed the relevant information in healthy controls. Different ethnicities were categorized as Asian, African and Caucasian. Subjects without exact ethnic information were classified as the mixed ethnic subgroup (Supplementary Tables 1 and 2).

\section{Statistical analysis}

Phenotypes and cancer risk As different laboratories adopted different methods or assays to test circulating concentrations of IGF1 and IGFBP3, we could not directly compare the reported values from these studies. Therefore, we used quantified meta-regression analyses for the associations of IGF1, IGFBP3 and/or IGF1/IGFBP3 molar ratio with cancer risk using random-effect model, based on DerSimonian and Laird method ${ }^{27}$ of maximally adjusted ORs (comparing the highest with the lowest category, Renehan et al. ${ }^{4}$ ) (Supplementary Table 3).

IGF1 and IGFBP3 polymorphisms and cancer risk IGF1 $(\mathrm{CA})_{\mathrm{n}}$, IGFBP3 A-202C and Gly32Ala polymorphisms were tested for their associations with cancer susceptibility based on different genetic models. For IGF1 (CA $)_{\mathrm{n}}$, the number of $(\mathrm{CA})_{\mathrm{n}}$ repeats being used in the analysis was either $n=19$ or other numbers for all the studies included in the final analysis (for example, dominant model: $\left(\mathrm{IGF} 1_{19 / 19}+\mathrm{IGF} 1_{19 / \text { non19 }}\right) \quad v s \quad \mathrm{IGF} 1_{\text {non19/non19; }}$ recessive model: IGF1 $19 / 19$ vs (IGF1 $1_{\text {non19/non19 }}+\mathrm{IGF}_{19 / \text { non19) }}$ ) and homozygote comparison: $\mathrm{IGF}_{19 / 19}$ vs IGF1 $1_{\text {non19/non19). }}$ ). Fixed-effect model, based on Mantel-Haenszel method, ${ }^{28}$ was used when no significant heterogeneity among the studies was found $(P>0.05)$. Otherwise, a random-effect model was chosen. Subgroup analyses, according to tumor types (if one tumor type was studied by fewer than three individual studies, it was classified as the 'other tumors' group), ethnicity, and study design (nested case-control, population-based case-control and hospital-based casecontrol) were also performed.

Genotype-phenotype correlation We also investigated the correlation between the two promoter polymorphisms, IGF1 (CA) $)_{\mathrm{n}}$ and IGFBP3 A-202C, and their phenotypes (circulating concentrations). For these two loci, two category mean levels were obtained to calculate the weight mean difference between the two homozygotes 
Table 1 Association between circulating concentrations of IGF1 (highest vs lowest) and cancer risk

\begin{tabular}{|c|c|c|c|c|c|c|}
\hline Variants & Category & Participants $\mathrm{Ca} / \mathrm{Co}$ No. & No. of studies & OR $(95 \% \mathrm{Cl})$ & $\mathrm{P}^{\mathrm{a}}$ & $\mathrm{P}^{\mathrm{b}}$ \\
\hline Overall effect & & $14489 / 27061$ & 63 & $1.15(1.03-1.29)$ & 0.014 & $<0.001$ \\
\hline \multirow{9}{*}{ Cancer site } & Prostate cancer & $5482 / 9415$ & 21 & $1.24(1.01-1.53)$ & 0.049 & 0.001 \\
\hline & Pre-menopausal breast cancer ${ }^{c}$ & $1525 / 2566$ & 11 & $1.52(1.23-1.88)$ & $<0.001$ & 0.421 \\
\hline & Post-menopausal breast cancer ${ }^{c}$ & $1142 / 1667$ & 9 & $1.02(0.78-1.34)$ & 0.885 & 0.576 \\
\hline & Colorectal cancer & $1909 / 3783$ & 9 & $1.28(1.02-1.61)$ & 0.031 & 0.328 \\
\hline & Endometrial cancer & $808 / 884$ & 5 & $0.68(0.43-1.06)$ & 0.376 & 0.258 \\
\hline & Lung cancer & $886 / 1841$ & 5 & $0.96(0.55-1.69)$ & 0.885 & 0.024 \\
\hline & Ovarian cancer & $627 / 1358$ & 4 & $0.93(0.51-1.67)$ & 0.799 & 0.034 \\
\hline & Pancreatic cancer & $374 / 1242$ & 3 & $0.87(0.57-1.33)$ & 0.507 & 0.547 \\
\hline & Other cancers & $1736 / 4305$ & 5 & $0.92(0.48-1.72)$ & 0.783 & $<0.001$ \\
\hline \multirow[t]{4}{*}{ Ethnic groups ${ }^{d}$} & Asian & $2109 / 4099$ & 10 & $1.34(1.06-1.71)$ & 0.016 & 0.238 \\
\hline & Caucasian & $7630 / 15076$ & 35 & $1.18(1.02-1.35)$ & 0.021 & 0.001 \\
\hline & African American & $430 / 490$ & 2 & $0.79(0.40-1.54)$ & 0.486 & 0.503 \\
\hline & Mixed race & $4320 / 7396$ & 16 & $1.14(0.76-1.35)$ & 0.924 & $<0.001$ \\
\hline \multirow[t]{3}{*}{ Study design ${ }^{\mathrm{e}}$} & Nested case-control & $10094 / 21065$ & 42 & $1.17(1.05-1.31)$ & 0.003 & 0.035 \\
\hline & P-based case-control & $1586 / 2138$ & 6 & $1.60(1.02-2.52)$ & 0.035 & 0.012 \\
\hline & H-based case-control & $2809 / 3858$ & 15 & $0.84(0.60-1.20)$ & 0.344 & $<0.001$ \\
\hline
\end{tabular}

${ }^{a} P$-value for a significant test.

${ }^{\mathrm{b}} P$ for the test of heterogeneity.

'Pre-menopausal and post-menopausal breast cancer patients were separately investigated.

${ }^{\mathrm{d}}$ A multiethnic study was divided according to ethnic group (eg, Asian, Caucasian and African).

"Prospective study was nominated as "Nested case-control study"; P-based case-control study: population-based case-control study; H-based casecontrol study: hospital-based case-control study.

$\left(I G F 1(\mathrm{CA})_{\mathrm{n}}\right.$ repeats: IGF1 $19 / 19$ vs IGF1 $1_{\text {non } 19 / \text { non } 19 ;}$ IGFBP3 A-202C: AA vs CC). A random-effect model was used to allow for heterogeneity among different studies. ${ }^{27}$

Test of heterogeneity and publication bias DerSimonian and Laird Q test was used to assess the degree of heterogeneity between studies and the heterogeneity was considered significant when $P<0.05 .{ }^{29}$ When the betweenstudy heterogeneity was found, a random-effect model was conducted. Sources of heterogeneity were determined by using random-effect meta-regression models with restricted maximum likelihood estimation. The inter-study variance $\left(\tau^{2}\right)$ was used to quantify the degree of heterogeneity between studies and the percentage of $\tau^{2}$ was used to describe the extent of explained heterogeneity. ${ }^{30}$ Publication bias was evaluated by the linear regression asymmetry test by Egger et $a l^{31}$

All data were analyzed in Statistical Analysis System software (v.9.1.3; SAS Institute, Cary, NC, USA), STATA7.0 (Stata-Corp, College Station, TX, USA) and Review Manager (v.4.2; Oxford, England). All $P$-values were based on two-sided tests and a $P$-value of less than 0.05 was considered statistically significant.

\section{Results}

\section{Phenotypes and cancer risk}

Sixty-five studies were included to assess the associations of IGF1 and IGFBP3 levels with cancer risk. Among them, there were 21 studies for prostate cancer, 11 for premenopausal breast cancer, 9 for post-menopausal breast cancer, 10 for colorectal cancer, 5 for lung cancer, 5 for endometrial cancer, 4 for ovarian cancer, 3 for pancreatic cancer and 5 for other tumors (Supplementary Table 1).

As a result, higher concentrations of IGF1 significantly increased $15 \%$ of overall cancer risk (OR, 1.15; 95\% CI, 1.03-1.29), especially increased risk of colorectal cancer (OR, 1.28; 95\% CI, 1.02-1.61), pre-menopausal breast cancer (OR, 1.52; 95\% CI, 1.23-1.88) and prostate cancer (OR, 1.24; 95\% CI, 1.01-1.53) (Table 1). In addition, we found that higher IGF1 significantly increased cancer risk among Asians (OR, 1.34; 95\% CI, 1.06-1.71) and Caucasians (OR, 1.18; 95\% CI, 1.02-1.35), in nested casecontrol studies (OR, 1.17; 95\% CI, 1.05-1.31) and population-based case-control studies (OR, 1.60; 95\% CI, 1.02-2.52) (Table 1).

For IGFBP3, 60 studies were eligible for phenotypecancer risk analysis. High levels of IGFBP3 significantly increased risk of pre-menopausal breast cancer (OR, 1.41; 95\% CI, 1.03-1.94), but they decreased risk of advanced prostate cancer risk by $56 \%$ (OR, $0.44 ; 95 \%$ CI, $0.25-0.77$ ) (Table 2, Figure 1). Twenty-one studies (4603 cases and 9165 controls) detected circulating levels of both IGF1 and IGFBP3, and evaluated the associations between their molar ratio and cancer risk. We found that higher IGF1/IGFBP3 molar ratio could increase colorectal cancer risk with borderline significance (OR, 1.70; 95\% CI, 0.98-2.96). 
Table 2 Circulating levels of IGF1, IGFBP3 relation to prostate cancer risk according to specific grade and stage

\begin{tabular}{|c|c|c|c|c|c|c|}
\hline Variants & Category & Participants Ca/Co No. & Selected studies & OR $(95 \% \mathrm{Cl})$ & $\mathrm{P}^{\mathrm{a}}$ & $P^{b}$ \\
\hline \multicolumn{7}{|l|}{ IGF1 } \\
\hline & Advanced prostate cancer ${ }^{\mathrm{c}}$ & $1464 / 1794$ & 4 & $2.40(1.49-3.87)$ & $<0.001$ & 0.445 \\
\hline & Localized prostate cancer ${ }^{c}$ & $1674 / 2108$ & 5 & $1.65(1.08-2.56)$ & 0.022 & 0.057 \\
\hline & Pooled effect ${ }^{\mathrm{e}}$ & $1674 / 2108$ & 5 & $1.96(1.36-2.83)$ & $<0.001$ & 0.254 \\
\hline & High-grade prostate cancer ${ }^{d}$ & $1798 / 1950$ & 4 & $1.27(0.83-1.93)$ & 0.268 & 0.318 \\
\hline & Low-grade prostate cancer ${ }^{d}$ & $1798 / 1950$ & 4 & $1.51(1.27-2.02)$ & 0.006 & 0.491 \\
\hline & Pooled effect $\mathrm{e}^{\mathrm{e}}$ & $1798 / 1950$ & 4 & $1.45(1.18-1.78)$ & $<0.001$ & 0.481 \\
\hline \multicolumn{7}{|l|}{ IGFBP3 } \\
\hline & Advanced prostate cancer $^{\mathrm{c}}$ & $1464 / 1794$ & 4 & $0.44(0.25-0.77)$ & 0.004 & 0.199 \\
\hline & Localized prostate cancer ${ }^{c}$ & $1674 / 2108$ & 5 & $0.97(0.75-1.26)$ & 0.844 & 0.459 \\
\hline & Pooled effect ${ }^{\mathrm{e}}$ & $1674 / 2108$ & 5 & $0.68(0.31-1.47)$ & 0.328 & 0.012 \\
\hline & High-grade prostate cancer ${ }^{d}$ & $1798 / 1950$ & 4 & $1.05(0.68-1.62)$ & 0.815 & 0.265 \\
\hline & Low-grade prostate cancer ${ }^{d}$ & $1798 / 1950$ & 4 & $0.95(0.70-1.27)$ & 0.713 & 0.403 \\
\hline & Pooled effect ${ }^{\mathrm{e}}$ & $1798 / 1950$ & 4 & $0.98(0.77-1.25)$ & 0.878 & 0.709 \\
\hline
\end{tabular}

${ }^{a} P$-value for a significant test.

${ }^{\mathrm{b}} \mathrm{P}$ for the test of heterogeneity.

${ }^{\mathrm{C} A d v a n c e d}$ prostate cancer: tumor stage: T3, T4 or N1, M1; localized prostate cancer: tumor stage: T1 or T2.

${ }^{\mathrm{d}}$ High-grade prostate cancer: Gleason $\geq 7$; low-grade prostate cancer: Gleason $<7$.

${ }^{\mathrm{e}}$ Three studies clearly stated the ORs and $95 \%$ Cls related to prostate cancer risk according to different tumor stage and tumor grade, ${ }^{47,51,54}$ and one study was only available in tumor grade, ${ }^{52}$ other two studies reported their results in different tumor stages, ${ }^{48,49}$ so available data was analyzed in the meta-analysis (including participants and selected ORs, 95\% Cls).

IGFI associated with advanced prostate cancer

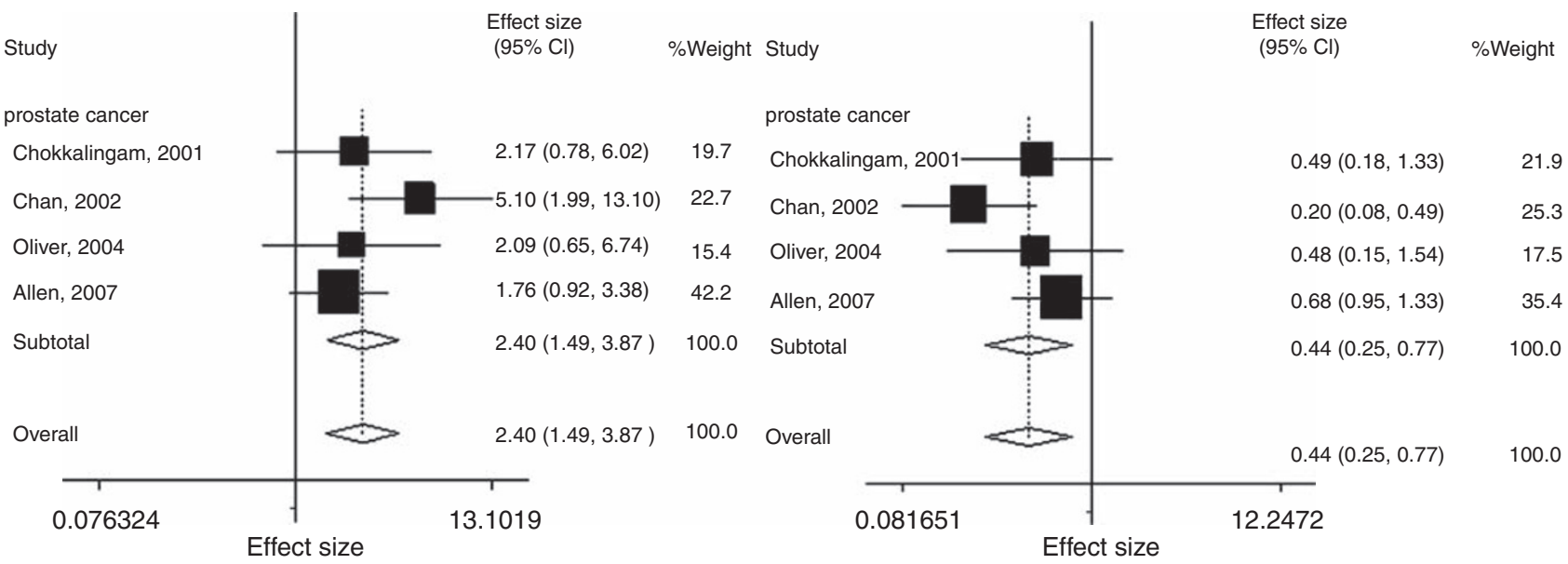

Figure 1 Circulating concentrations of IGF1 or IGFBP3 relation to prostate cancer risks.

\section{Functional polymorphisms and cancer risk}

Twenty-seven studies investigated the polymorphisms and cancer risk (19 for IGF1 (CA), 16 for IGFBP3 A-202C and 6 for IGFBP3 Gly32Ala) (Supplementary Table 2). For $I G F 1(\mathrm{CA})_{\mathrm{n}}$, we did not find any significant main effects on cancer risk in both dominant and recessive models (OR, 1.06; 95\% CI, $0.93-1.20$ in a dominant model; OR, 0.95; 95\% CI, 0.90-1.01 in a recessive model). In the stratified analysis by race, common allele IGF1 $(\mathrm{CA})_{19}$ significantly increased cancer risk among Asians in the dominant model and homozygote comparison (pooled ORs (95\% CIs): $1.29(1.13-1.47)$ in the dominant model; 1.26(1.02-1.57) in homozygote comparison, respectively), but not among other ethnicities (data not shown).

For IGFBP3 A-202C, variant allele was not associated with overall cancer risk either in dominant (OR, 1.03; 95\% CI, 0.97-1.10) or recessive models (OR, 1.02; 95\% CI, 0.97-1.06, Supplemental Figure 1). However, -202C significantly contributed to breast cancer risk in the dominant genetic model (OR, 1.07; 95\% CI, 1.01-1.13). 
Table 3 Functional polymorphisms of IGFBP3 (A-202C and Gly32Ala) and cancer risks

\begin{tabular}{|c|c|c|c|c|c|c|c|}
\hline Variants & Comparison & Category & Study No. ${ }^{a}$ & $\mathrm{Ca} / \mathrm{Co} \mathrm{No}^{\mathrm{a}}$ & OR $(95 \% \mathrm{Cl})$ & $\mathrm{P}^{\mathrm{b}}$ & $\mathrm{P}^{\mathrm{C}}$ \\
\hline \multirow[t]{15}{*}{ IGFBP3 A-202C } & \multirow[t]{5}{*}{$(\mathrm{AC}+\mathrm{CC})$ vs $\mathrm{AA}$ Dominant model } & 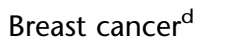 & 4 & $15767 / 21942$ & $1.07(1.01-1.13)$ & 0.020 & 0.40 \\
\hline & & Colorectal cancer & 3 & $2834 / 3520$ & $0.97(0.86-1.09)$ & 0.610 & 0.810 \\
\hline & & Prostate cancer & 7 & $2041 / 2318$ & $1.04(0.97-1.10)$ & 0.450 & 0.070 \\
\hline & & Other cancers & 2 & $785 / 856$ & $0.77(0.34-1.77)$ & 0.540 & $<0.001$ \\
\hline & & Overall effects $\mathrm{e}^{\mathrm{e}}$ & 16 & $21427 / 28636$ & $1.03(0.97-1.10)$ & 0.280 & 0.010 \\
\hline & \multirow[t]{5}{*}{$\mathrm{CC}$ vs $(\mathrm{AC}+\mathrm{AA})$ Recessive model } & Breast cancer & 4 & $15767 / 21942$ & $1.02(0.98-1.07)$ & 0.340 & 0.360 \\
\hline & & Colorectal cancer & 3 & $2834 / 3520$ & $0.93(0.83-1.05)$ & 0.260 & 0.360 \\
\hline & & Prostate cancer & 6 & $1944 / 2226$ & $1.13(0.97-1.31)$ & 0.110 & 0.820 \\
\hline & & Other cancers & 2 & $785 / 856$ & $0.74(0.48-1.14)$ & 0.170 & 0.001 \\
\hline & & Overall effects ${ }^{\mathrm{e}}$ & 15 & $21330 / 28544$ & $1.02(0.97-1.06)$ & 0.450 & 0.10 \\
\hline & \multirow[t]{5}{*}{$\mathrm{CC}$ vs $\mathrm{AA}$} & Breast cancer & 4 & $8355 / 11674$ & $1.04(0.94-1.15)$ & 0.490 & 0.007 \\
\hline & & Colorectal cancer & 3 & $1452 / 1851$ & $1.65(0.74-3.67)$ & 0.220 & $<0.001$ \\
\hline & & Prostate cancer & 5 & $801 / 765$ & $1.18(0.99-1.41)$ & 0.070 & 0.420 \\
\hline & & Other cancers & 2 & $520 / 537$ & $0.45(0.06-3.30)$ & 0.430 & $<0.00$ \\
\hline & & Overall effects ${ }^{\mathrm{e}}$ & 15 & $11378 / 15232$ & $1.08(0.96-1.21)$ & 0.220 & $<0.00$ \\
\hline \multirow[t]{2}{*}{ IGFBP3 Gly32Ala } & (Gly/Ala+Ala/Ala) vs (Gly/Glya) & Overall effects & 6 & $4477 / 5443$ & $1.15(0.82-1.43)$ & 0.220 & $<0.001$ \\
\hline & (Ala/Ala) vs (Gly/Ala+Gly/Glya) & Overall effects & 6 & $4477 / 5443$ & $1.12(0.85-1.49)$ & 0.410 & $<0.001$ \\
\hline
\end{tabular}

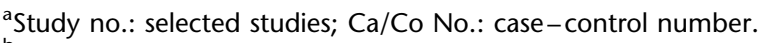

${ }^{\mathrm{b}} P$-value for a significant test.

${ }^{c} P$ for the test of heterogeneity.

${ }^{\mathrm{d} A}$ multicenter study conducted by COX et al was divided to 10 substudies by a different plan.

${ }^{\mathrm{e}}$ Available data was analyzed in the respective comparison category.
}

We also observed that $-202 \mathrm{C}$ allele was associated with a $13 \%$ increased risk of prostate cancer in the recessive model (OR, 1.13; 95\% CI, 0.97-1.31). However, the effect was not statistically significant $(P=0.110)$. For IGFBP3 Gly32Ala, no significant associations were found (Table 3 ).

\section{Genotype-phenotype correlation}

The two promoter polymorphisms, IGF $(\mathrm{CA})_{\mathrm{n}}$ and IGFBP3 A-202C, were suggested to be associated with transcription activity of their target genes. ${ }^{32,33}$ To further evaluate the genotype-phenotype correlations, we conducted the analyses between these genetic variants and circulating levels of IGF1 and IGFBP3 in healthy controls. Five studies were available for the analysis between IGF1 (CA)n polymorphism and IGF1 levels, ${ }^{11,34-37}$ but no significant correlation was found (Table 4). Notably, five studies were available for the correlation analysis between IGFBP3 A-202C and circulating levels of IGFBP3, ${ }^{9,16,25,37,38}$ and we found that the circulating IGFBP3 could be influenced by A-202C (AA vs CC: weight mean difference, $545.97 \mathrm{ng} / \mathrm{ml}$; 95\% CI, 412.38-679.56; $P<0.001$ ) (Table 4, Figure 2).

\section{Test of heterogeneity and publication bias}

We evaluated the sources of heterogeneity in relation to cancer site, study design and ethnicity. We found that the cancer site could explain substantial altered heterogeneity among studies focusing on phenotypes and cancer risk (55.1, 27.0 and $52.7 \%$ for IGF1, IGFBP3 and their molar ratio, respectively). For example, higher levels of IGF1 significantly increased the risk of prostate cancer, premenopausal breast cancer and colorectal cancer (OR, 1.24; 95\% CI, 1.01-1.53, OR, 1.52; 95\% CI, 1.23-1.88 and OR,
1.28; 95\% CI, 1.02-1.61, respectively), but no significant evidence was found in other cancer sites (Table 1). For IGF1 phenotype, increased risks were found in both nested and population-based case-control studies, but disappeared in hospital-based studies (OR, 1.17; 95\%, 1.05-1.31; OR, 1.60; 95\%, 1.02-2.52 and OR, 0.84; 95\%, 0.60-1.20, respectively). Higher levels of IGF1 increased cancer risk in Asians and Caucasians, but not in Africans. Therefore, study design and ethnicity contributed 28 and $11.6 \%$, respectively, of the heterogeneity. As for the association between polymorphisms of IGF1 or IGFBP3 and cancer risk, the three factors (ethnicity, cancer site, study design) combined contributed more than 90\% heterogeneity of $\imath^{2}$ totally.

Egger's test was used to detect the potential publication bias, which was more pronounced when the higher intercept deviated from zero in linear regression analysis. We did not find significant publication bias for circulating levels of IGF1 and IGF1/IGFBP3 molar ratio ( $P$-value, 0.522 and 0.531 , respectively), polymorphisms of IGFBP3 A-202C and Gly32Ala ( $P$-value, 0.106 and 0.805, respectively). However, for circulating levels of IGFBP3 and IGF1 $(\mathrm{CA})_{\mathrm{n}}$ polymorphism, publication bias was significant ( $P$ all $<0.001)$.

\section{Discussion}

In this meta-analysis, we systematically investigated the relationship between IGF1 or IGFBP3 genotypes and phenotypes and cancer risk. We found that higher circulating concentrations of IGF1 were significantly 


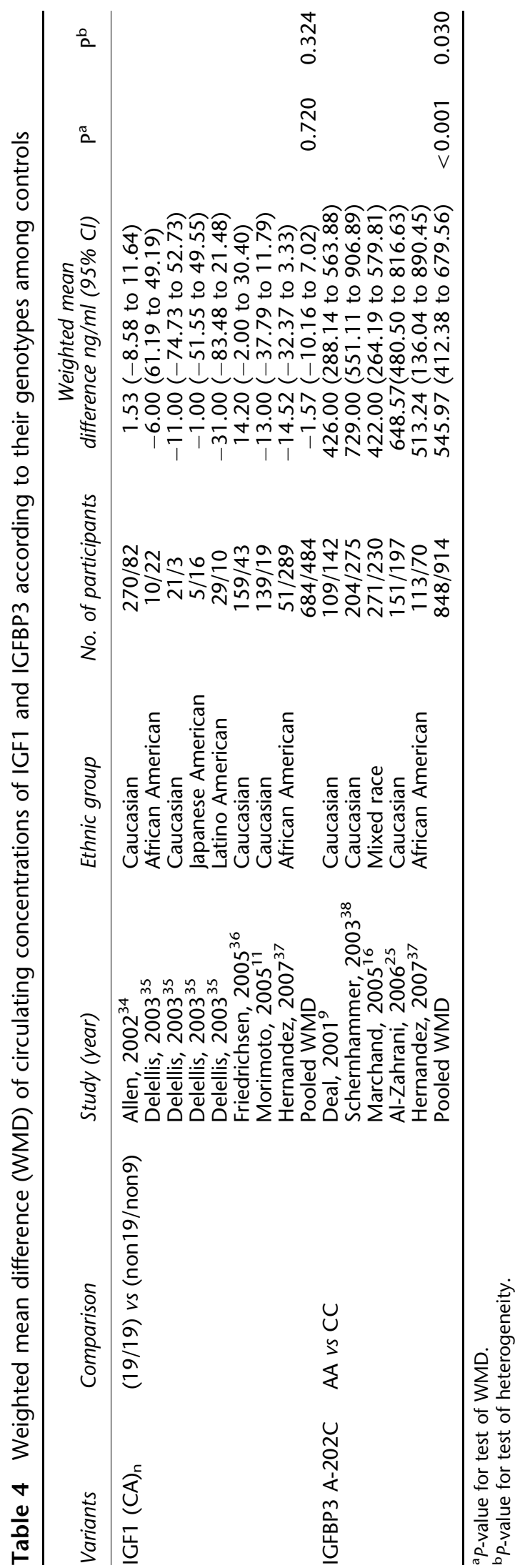

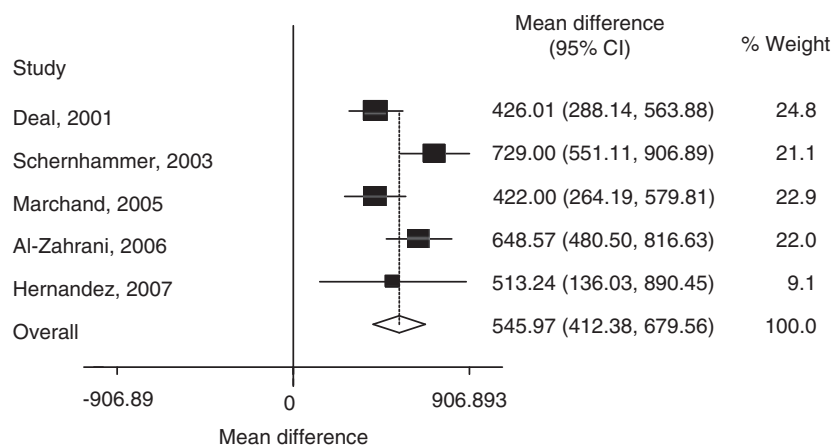

Figure 2 Weighted mean difference in circulating concentrations of IGFBP3 genotypes (AA vs CC) among controls.

associated with increased risk of all cancers combined, especially in cancers of pre-menopausal breast, colorectal and prostate. In addition, higher circulating levels of IGFBP3 significantly decreased risk of advanced prostate cancer. Meanwhile, IGFBP3 promoter polymorphism, A-202C, was associated with an increased prostate cancer risk and modified the circulating levels of IGFBP3.

IGF1 and IGFBP3 has an important role in tumor development. ${ }^{3,4}$ From the present pooled analyses, we found that higher concentrations of IGF1 were significantly associated with an increased risk of pre-menopausal breast cancer but not of post-menopausal breast cancer, which was consistent with previously published studies. ${ }^{4,39,40}$ It was reported that estrogen could interact with IGF1 to increase cell proliferation, particularly in breast cancer cells. ${ }^{41}$ In addition, both estrogen ${ }^{42}$ and IGF1 levels were higher in pre-menopausal breast cancer than those in post-menopausal breast cancer, suggesting that IGF1 might have a different role in pre- and postmenopausal breast cancers. We also found that higher circulating levels of IGFBP3 were significantly associated with altered risk of pre-menopausal breast cancer, which was consistent with Renehan's conclusion. ${ }^{4}$ It was reported that IGFBP3 could play an anti-apoptotic role in Hs578T breast cancer cells. ${ }^{43}$ Besides, body size, vigorous physical activity, and dietary factors could influence IGF1 and IGFBP3 molar ratio in pre-menopausal breast cancer women more than postmenopausal breast cancer women, ${ }^{44}$ and they might account for the different roles of IGF1 and IGFBP3 in breast cancer according to menopausal status.

IGF1 could also modulate androgen receptor (AR) activity by PI3K/Akt or Ras/MAPK pathway, leading to AR phosphorylation and sensitization to low concentrations of androgens, ${ }^{45}$ suggesting that IGF1 might play a crucial role in prostate cancer. It was reported that IGF1 could induce ligand-independent activation of AR and enhance the expression of matrix metalloproteinase-2. ${ }^{46}$ In this meta-analysis, the effects of circulating levels of IGF1, IGFBP3 and IGFBP3 A-202C polymorphism were more 
pronounced in prostate cancer risk. Furthermore, 11 of 21 prostate cancer studies stated tumor stage or grade information, ${ }^{47-57}$ although only six studies addressed the impact of IGF or IGFBP3 on specific stage and grade with the uniform criteria. ${ }^{47-49,51,52,54}$ We found that high concentrations of IGF1 significantly increased risk of advanced prostate cancer, whereas high levels of IGFBP3 significantly decreased risk of advanced prostate cancer, suggesting that circulating concentrations of IGF1 and/or IGFBP3 might play adverse roles in prostate carcinogenesis.

Although the number of CA repeats in the promoter region of $I G F 1$ was reported to be inversely associated with transcription activity, ${ }^{7,8}$ in this analysis, this functional polymorphism of IGF1 (CA) n was not significantly associated with cancer risk, which was consistent with a previously published meta-analysis (17 studies, 8799 cases and 13901 controls). ${ }^{22}$ However, IGF1 (CA) 19/19 $_{19}$ was significantly associated with cancer risk among Asians in dominant genetic model and homozygote comparison, which needs further evaluation. Although IGFBP3 A-202C was non-significantly associated with overall cancer risk, this functional locus was related to a significantly increased risk of breast cancer in the dominant model, and prostate cancer risk in the recessive model and homozygote comparison with borderline significance. Furthermore, we found that the -202CC genotype correlated to lower concentrations of IGFBP3 among controls, whereas decreased IGFBP3 levels were associated with an increased risk of advanced prostate cancer.

Apart from cancer site, other factors might also account for heterogeneity across studies, such as ethnicity and study design. Study design and ethnicity contribute much to the heterogeneity for the association between circulating levels of IGF1 and cancer risk. The results of population-based case-control studies were comparable with those of nested case-control studies, but were different from those of hospital-based case-control studies. It is possible that hospital-based case-control studies might suffer from selection bias of study subjects. As for ethnicity, however, only two studies and limited number of patients were available for Africans, which limited us to detect stable effects in this population, and more populationbased or prospective studies are needed.

As a meta-analysis of observational studies, our results have some potential limitations. Firstly, this type of metaanalysis is vulnerable to biases inherent in the original studies. ${ }^{4}$ Secondly, further analysis for some important confounding factors such as body mass index and physical activity were neglected because of limited information from original studies, although these two factors might influence the concentrations of IGF1 or IGFBP3. Further larger studies with both genotypes and phenotypes of IGF1and IGFBP3 with functional evaluations, and geneenvironmental interactions on the risk of different cancers are warranted.

\section{Acknowledgements}

This work was supported in part by a Program for Changjiang Scholars and Innovative Research Team in University (IRT0631).

\section{References}

1 Khandwala HM, McCutcheon IE, Flyvbjerg A, Friend KE: The effects of insulin-like growth factors on tumorigenesis and neoplastic growth. Endocr Rev 2000; 21: 215-244.

2 Pollak M: Insulin-like growth factor physiology and cancer risk. Eur J Cancer 2000; 36: 1224-1228.

3 Furstenberger G, Senn HJ: Insulin-like growth factors and cancer. Lancet Oncol 2002; 3: 298-302.

4 Renehan AG, Zwahlen M, Minder C, O'Dwyer ST, Shalet SM, Egger M: Insulin-like growth factor (IGF)-I, IGF binding protein-3, and cancer risk: systematic review and meta-regression analysis. Lancet 2004; 363: 1346-1353.

5 Lacey Jr JV, Potischman N, Madigan MP et al: Insulin-like growth factors, insulin-like growth factor-binding proteins, and endometrial cancer in postmenopausal women: results from a US case-control study. Cancer Epidemiol Biomarkers Prev 2004; 13: 607-612.

6 Hong Y, Pedersen NL, Brismar K, Hall K, de Faire U: Quantitative genetic analyses of insulin-like growth factor I (IGF-I), IGFbinding protein-1, and insulin levels in middle-aged and elderly twins. J Clin Endocrinol Metab 1996; 81: 1791-1797.

7 Tae HJ, Luo X, Kim KH: Roles of CCAAT/enhancer-binding protein and its binding site on repression and derepression of acetyl-CoA carboxylase gene. J Biol Chem 1994; 269: 1047510484.

8 Gebhardt F, Zanker KS, Brandt B: Modulation of epidermal growth factor receptor gene transcription by a polymorphic dinucleotide repeat in intron 1. J Biol Chem 1999; 274: 13176-13180.

9 Deal C, Ma J, Wilkin F et al: Novel promoter polymorphism in insulin-like growth factor-binding protein-3: correlation with serum levels and interaction with known regulators. J Clin Endocrinol Metab 2001; 86: 1274-1280.

10 Jernstrom H, Deal C, Wilkin F et al: Genetic and nongenetic factors associated with variation of plasma levels of insulin-like growth factor-I and insulin-like growth factor-binding protein-3 in healthy premenopausal women. Cancer Epidemiol Biomarkers Prev 2001; 10: 377-384.

11 Morimoto LM, Newcomb PA, White E, Bigler J, Potter JD: Insulinlike growth factor polymorphisms and colorectal cancer risk. Cancer Epidemiol Biomarkers Prev 2005; 14: 1204-1211.

12 Ren Z, Cai Q, Shu XO et al: Genetic polymorphisms in the IGFBP3 gene: association with breast cancer risk and blood IGFBP-3 protein levels among Chinese women. Cancer Epidemiol Biomarkers Prev 2004; 13: 1290-1295.

13 Cleveland RJ, Gammon MD, Edmiston SN et al: IGF1 CA repeat polymorphisms, lifestyle factors and breast cancer risk in the Long Island Breast Cancer Study Project. Carcinogenesis 2006; 27: 758- 765 .

14 Cox A, Dunning AM, Garcia-Closas M et al: A common coding variant in CASP8 is associated with breast cancer risk. Nat Genet 2007; 39: 352-358.

15 Wang L, Habuchi T, Tsuchiya $\mathrm{N}$ et al: Insulin-like growth factorbinding protein-3 gene -202 A/C polymorphism is correlated with advanced disease status in prostate cancer. Cancer Res 2003; 63: $4407-4411$.

16 Le Marchand L, Kolonel LN, Henderson BE, Wilkens LR: Association of an exon 1 polymorphism in the IGFBP3 gene with circulating IGFBP-3 levels and colorectal cancer risk: the multiethnic cohort study. Cancer Epidemiol Biomarkers Prev 2005; 14: $1319-1321$.

17 Chen W, Wang L, Ke Q et al: The role of IGFBP3 functional polymorphisms in the risk of gastric cancer in a high-risk Chinese population. Eur J Cancer Prev 2008; 17: 82-87. 
18 Fletcher $\mathrm{O}$, Gibson L, Johnson $\mathrm{N}$ et al: Polymorphisms and circulating levels in the insulin-like growth factor system and risk of breast cancer: a systematic review. Cancer Epidemiol Biomarkers Prev 2005; 14: 2-19.

19 Gonzalez-Zuloeta Ladd AM, Liu F, Houben MP et al: IGF-1 CA repeat variant and breast cancer risk in postmenopausal women. Eur J Cancer 2007; 43: 1718-1722.

20 Giovannucci E: Insulin, insulin-like growth factors and colon cancer: a review of the evidence. J Nutr 2001; 131: 3109S-3120S.

21 Morris JK, George LM, Wu T, Wald NJ: Insulin-like growth factors and cancer: no role in screening. Evidence from the BUPA study and meta-analysis of prospective epidemiological studies. $\mathrm{Br} J$ Cancer 2006; 95: 112-117.

22 Chen X, Guan J, Song Y et al: IGF-I (CA) repeat polymorphisms and risk of cancer: a meta-analysis. J Hum Genet 2008; 53: 227-238.

23 Lukanova A, Lundin E, Toniolo P et al: Circulating levels of insulin-like growth factor-I and risk of ovarian cancer. Int J Cancer 2002; 101: 549-554.

24 Otani T, Iwasaki M, Sasazuki S, Inoue M, Tsugane S: Plasma Cpeptide, insulin-like growth factor-I, insulin-like growth factor binding proteins and risk of colorectal cancer in a nested casecontrol study: the Japan public health center-based prospective study. Int I Cancer 2007; 120: 2007-2012.

25 Al-Zahrani A, Sandhu MS, Luben RN et al: IGF1 and IGFBP3 tagging polymorphisms are associated with circulating levels of IGF1, IGFBP3 and risk of breast cancer. Hum Mol Genet 2006; 15: 1-10.

26 Rohrbacher M, Risch A, Kropp S, Chang-Claude J: The A(-336C) insulin-like growth factor binding protein-3 promoter polymorphism is not a modulator of breast cancer risk in Caucasian women. Cancer Epidemiol Biomarkers Prev 2005; 14: 289-290.

27 DerSimonian R, Laird N: Meta-analysis in clinical trials. Control Clin Trials 1986; 7: 177-188.

28 Mantel N, Haenszel W: Statistical aspects of the analysis of data from retrospective studies of disease. J Natl Cancer Inst 1959; 22: $719-748$.

29 Deeks JJ: Systematic reviews in health care: Systematic reviews of evaluations of diagnostic and screening tests. BMJ 2001; 323: $157-162$.

30 Lau J, Ioannidis JP, Schmid CH: Quantitative synthesis in systematic reviews. Ann Intern Med 1997; 127: 820-826.

31 Egger M, Davey Smith G, Schneider M, Minder C: Bias in metaanalysis detected by a simple, graphical test. BMJ 1997; 315: 629-634.

32 Martin JL, Coverley JA, Pattison ST, Baxter RC: Insulin-like growth factor-binding protein-3 production by MCF-7 breast cancer cells: stimulation by retinoic acid and cyclic adenosine monophosphate and differential effects of estradiol. Endocrinology 1995; 136: 1219-1226.

33 Gucev ZS, Oh Y, Kelley KM, Rosenfeld RG: Insulin-like growth factor binding protein 3 mediates retinoic acid- and transforming growth factor beta2-induced growth inhibition in human breast cancer cells. Cancer Res 1996; 56: 1545-1550.

34 Allen NE, Davey GK, Key TJ, Zhang S, Narod SA: Serum insulinlike growth factor I (IGF-I) concentration in men is not associated with the cytosine-adenosine repeat polymorphism of the IGF-I gene. Cancer Epidemiol Biomarkers Prev 2002; 11: 319-320.

35 DeLellis K, Ingles S, Kolonel L et al: IGF1 genotype, mean plasma level and breast cancer risk in the Hawaii/Los Angeles multiethnic cohort. Br J Cancer 2003; 88: 277-282.

36 Friedrichsen DM, Hawley S, Shu J et al: IGF-I and IGFBP-3 polymorphisms and risk of prostate cancer. Prostate 2005; 65: 44-51.

37 Hernandez W, Grenade C, Santos ER, Bonilla C, Ahaghotu C, Kittles RA: IGF-1 and IGFBP-3 gene variants influence on serum levels and prostate cancer risk in African-Americans. Carcinogenesis 2007; 28: 2154-2159.

38 Schernhammer ES, Hankinson SE, Hunter DJ, Blouin MJ, Pollak MN: Polymorphic variation at the -202 locus in IGFBP3:
Influence on serum levels of insulin-like growth factors, interaction with plasma retinol and vitamin $\mathrm{D}$ and breast cancer risk. Int J Cancer 2003; 107: 60-64.

39 Shi R, Yu H, McLarty J, Glass J: IGF-I and breast cancer: a metaanalysis. Int J Cancer 2004; 111: 418-423.

40 Sugumar A, Liu YC, Xia Q, Koh YS, Matsuo K: Insulin-like growth factor (IGF)-I and IGF-binding protein 3 and the risk of premenopausal breast cancer: a meta-analysis of literature. Int $J$ Cancer 2004; 111: 293-297.

41 Yee D, Lee AV: Crosstalk between the insulin-like growth factors and estrogens in breast cancer. J Mammary Gland Biol Neoplasia 2000; 5: 107-115.

42 Clemons M, Goss P: Estrogen and the risk of breast cancer. N Engl J Med 2001; 344: 276-285.

43 McCaig C, Perks CM, Holly JM: Intrinsic actions of IGFBP-3 and IGFBP-5 on Hs578T breast cancer epithelial cells: inhibition or accentuation of attachment and survival is dependent upon the presence of fibronectin. J Cell Sci 2002; 115: 4293-4303.

44 Slattery ML, Baumgartner KB, Byers $\mathrm{T}$ et al: Genetic, anthropometric, and lifestyle factors associated with IGF-1 and IGFBP-3 levels in Hispanic and non-Hispanic white women. Cancer Causes Control 2005; 16: 1147-1157.

45 Papatsoris AG, Karamouzis MV, Papavassiliou AG: Novel insights into the implication of the IGF-1 network in prostate cancer. Trends Mol Med 2005; 11: 52-55.

46 Heinlein CA, Chang C: Androgen receptor in prostate cancer. Endocr Rev 2004; 25: 276-308.

47 Chan JM, Stampfer MJ, Ma J et al: Insulin-like growth factor-I (IGF-I) and IGF binding protein-3 as predictors of advanced-stage prostate cancer. J Natl Cancer Inst 2002; 94: 1099-1106.

48 Chokkalingam AP, Pollak M, Fillmore CM et al: Insulin-like growth factors and prostate cancer: a population-based casecontrol study in China. Cancer Epidemiol Biomarkers Prev 2001; 10: $421-427$.

49 Wolk A, Mantzoros CS, Andersson SO et al: Insulin-like growth factor 1 and prostate cancer risk: a population-based, case-control study. I Natl Cancer Inst 1998; 90: 911-915.

$50 \mathrm{Li} \mathrm{L}$, Yu H, Schumacher F, Casey G, Witte JS: Relation of serum insulin-like growth factor-I (IGF-I) and IGF binding protein-3 to risk of prostate cancer (United States). Cancer Causes Control 2003; 14: $721-726$.

51 Oliver SE, Holly J, Peters TJ et al: Measurement of insulin-like growth factor axis does not enhance specificity of PSA-based prostate cancer screening. Urology 2004; 64: 317-322.

52 Platz EA, Pollak MN, Leitzmann MF, Stampfer MJ, Willett WC, Giovannucci E: Plasma insulin-like growth factor-1 and binding protein-3 and subsequent risk of prostate cancer in the PSA era. Cancer Causes Control 2005; 16: 255-262.

53 Severi G, Morris HA, MacInnis RJ et al: Circulating insulin-like growth factor-I and binding protein-3 and risk of prostate cancer. Cancer Epidemiol Biomarkers Prev 2006; 15: 1137-1141.

54 Allen NE, Key TJ, Appleby PN et al: Serum insulin-like growth factor (IGF)-I and IGF-binding protein-3 concentrations and prostate cancer risk: results from the European Prospective Investigation into Cancer and Nutrition. Cancer Epidemiol Biomarkers Prev 2007; 16: 1121-1127.

55 Stattin P, Rinaldi S, Biessy C, Stenman UH, Hallmans G, Kaaks R: High levels of circulating insulin-like growth factor-I increase prostate cancer risk: a prospective study in a population-based nonscreened cohort. J Clin Oncol 2004; 22: 3104-3112.

56 Weiss JM, Huang WY, Rinaldi S et al: IGF-1 and IGFBP-3: Risk of prostate cancer among men in the Prostate, Lung, Colorectal and Ovarian Cancer Screening Trial. Int I Cancer 2007; 121: 2267-2273.

57 Chen C, Lewis SK, Voigt L, Fitzpatrick A, Plymate SR, Weiss NS: Prostate carcinoma incidence in relation to prediagnostic circulating levels of insulin-like growth factor I, insulin-like growth factor binding protein 3 , and insulin. Cancer 2005; 103: 76-84.

Supplementary Information accompanies the paper on European Journal of Human Genetics website (http://www.nature.com/ejhg) 